\title{
Correction to: Intraoperative conversion from laparoscopic gastrectomy to an open procedure: a decade of experience in a Japanese high-volume center
}

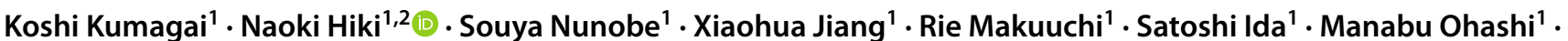 \\ Toshiharu Yamaguchi ${ }^{1} \cdot$ Takeshi Sano $^{1}$
}

Published online: 7 July 2020

(c) Springer Science+Business Media, LLC, part of Springer Nature 2020

\section{Correction to: Surgical Endoscopy https://doi.org/10.1007/s00464-020-07584-7}

In the last paragraph in the "Materials and methods" section of the original article, we clarified that this study was conducted in accordance with the International Conference on Harmonization of Guidelines for Good Clinical Practice, but it was incorrect.

This study was conducted in accordance with the Ethical Guidelines of Japan Ministry of Health, Labour and Welfare for Medical and Health Research Involving Human
Subjects and conformed to the provisions of the Declaration of Helsinki.

Publisher's Note Springer Nature remains neutral with regard to jurisdictional claims in published maps and institutional affiliations.
The original article can be found online at https://doi.org/10.1007/ s00464-020-07584-7.

Naoki Hiki

naoki.hiki@jfcr.or.jp; nhiki@med.kitasato-u.ac.jp

1 Department of Gastroenterological Surgery, Cancer Institute Hospital of JFCR, 3-8-31 Ariake, Koto-ku, Tokyo 135-8550, Japan

2 Department of Upper Gastrointestinal Surgery, Kitasato University School of Medicine, 1-15-1 Kitasato, Minami-ku, Sagamihara, Kanagawa 252-0374, Japan 